\title{
Papers
}

\section{Systematic review and economic evaluation of Helicobacter pylori eradication treatment for non-ulcer dyspepsia}

\author{
Paul Moayyedi, Shelly Soo, Jonathan Deeks, David Forman, James Mason, Michael Innes, \\ Brendan Delaney on behalf of the Dyspepsia Review Group
}

\begin{abstract}
Objectives To evaluate efficacy and cost effectiveness of Helicobacter pylori eradication treatment in patients with non-ulcer dyspepsia infected with $H$ pylori. Design Systematic review of randomised controlled trials comparing $H$ pylori eradication with placebo or another drug treatment. Results were incorporated into a Markov model comparing health service costs and benefits of $H$ pylori eradication with antacid treatment over one year.

Data sources Six electronic databases were searched for randomised controlled trials from January 1966 to May 2000. Experts in the field, pharmaceutical companies, and journals were contacted for information on any unpublished trials. Trial reports were reviewed according to predefined eligibility and quality criteria.
\end{abstract}

Main outcome measures Relative risk reduction for remaining dyspeptic symptoms (the same or worse) at 3-12 months. Cost per dyspepsia-free month estimated from Markov model based on estimated relative risk reduction.

Results Twelve trials were included in the systematic review, nine of which evaluated dyspepsia at 3-12 months in 2541 patients. H pylori eradication treatment was significantly superior to placebo in treating non-ulcer dyspepsia (relative risk reduction $9 \%(95 \%$ confidence interval $4 \%$ to $14 \%))$, one case of dyspepsia being cured for every 15 people treated. $H$ pylori eradication cost $£ 56$ per dyspepsia-free month during first year after treatment.

Conclusion $H$ pylori eradication may be cost effective treatment for non-ulcer dyspepsia in infected patients but further evidence is needed on decision makers' willingness to pay for relief of dyspepsia.

\section{Introduction}

There is unequivocal evidence that infection with Helicobacter pylori is the principal cause of peptic ulcer disease. The organism is present in $85-95 \%$ of patients with peptic ulcer disease, and treating the infection is effective in healing these ulcers. ${ }^{1}$ Treatment to eradicate $H$ pylori results in permanent cure of peptic ulcer disease, whereas $60-80 \%$ of such patients relapse within a year if treated with antisecretory drugs alone.
The evidence for an association between $H$ pylori and non-ulcer dyspepsia is more uncertain. Many trials evaluating the efficacy of $H$ pylori eradication treatment for non-ulcer dyspepsia have been poorly designed and have given conflicting results. ${ }^{2}$ A recent review of the literature indicated that $H$ pylori eradication treatment is effective in non-ulcer dyspepsia, ${ }^{3}$ but the results of other reviews that include more recent trials have been less clear. ${ }^{45}$

Several well designed trials have been published in the past two years. These have also given conflicting results, suggesting that any effect of $H$ pylori eradication treatment on non-ulcer dyspepsia is at best small and may not be an efficient use of resources. We have conducted a rigorous systematic review of available randomised trials and performed an economic analysis of the results to establish whether $H$ pylori eradication is a cost effective treatment for non-ulcer dyspepsia.

\section{Methods}

\section{Systematic review}

Search strategy

Randomised controlled trials fulfilling the eligibility criteria listed in the box were suitable for inclusion in the review, regardless of language and publication status. We identified studies by searching six electronic databases using both subject terms and text words; by reviewing bibliographies of retrieved trials; by contacting experts in 15 countries and pharmaceutical companies; and by requesting information of articles in peer review or in press from editors of general medical and gastroenterology journals (full details of the searches are given on the $B M J$ s website). Electronic searches were initially undertaken in March 1999, and updated in May 2000. In addition, we routinely scanned general medical and major gastroenterology journals over the previous year to ensure inclusion of the most recent studies.

Assessment of eligibility and trial quality

Dyspepsia was defined according to published definitions. ${ }^{67}$ Two investigators independently reviewed all identified papers according to the eligibility and quality criteria. Abstracts were not included unless further details were available from the authors.

\section{Editorial by van Zanten \\ Gastroenterology Unit, Centre for Digestive Diseases, General Infirmary at Leeds, Leeds LS1 3EX Paul Moayyedi senior lecturer Shelly Soo research fellow \\ Systematic Review Development \\ Programme, ICRF/ \\ NHS Centre for \\ Statistics in \\ Medicine, Institute \\ of Health Sciences, \\ Oxford OX3 7LF \\ Jonathan Deeks \\ head \\ Cochrane Upper Gastrointestinal and Pancreatic Diseases \\ Group, University \\ of Leeds, Leeds \\ LS2 9LN \\ David Forman professor of cancer epidemiology \\ Centre for Health Economics, University of York, York YO1 5DD \\ James Mason \\ senior lecturer in health economics \\ continued over}

BMJ 2000;321:659-64

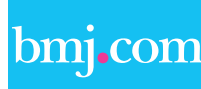

Details of search strategy and of trials identified in search appear on the BMJ's website 
Department of General Practice, University of Birmingham, Medical School, Birmingham B15 2TT

Michael Innes research fellow Brendan Delaney senior lecturer

Correspondence to: B Delaney B.C.Delaney@ bham.ac.uk

\section{Eligibility and quality criteria}

\section{Eligibility criteria}

- Randomised controlled trial

- Patients with dyspepsia defined as "any upper gastrointestinal symptoms referable to the gastrointestinal tract," which includes dyspepsia defined according to the working group criteria $(1989)^{6}$ and the Rome criteria (1991). ${ }^{7}$ Trials that included only patients with heartburn and acid reflux were excluded

- Peptic ulcer disease and oesophagitis were previously excluded in all participants by endoscopy or barium meal

- Intervention group received effective $H$ pylori eradication treatment (see below), while comparison group received placebo or other drugs known not to eradicate $H$ pylori

- Suitable $H$ pylori eradication treatments were Proton pump inhibitor dual treatment-Proton pump inhibitor plus either amoxicillin or clarithromycin for two weeks

New triple treatment-Proton pump inhibitor, $\mathrm{H}_{2}$ receptor antagonist, or ranitidine bismuth citrate with two out of three of amoxicillin, clarithromycin, and 5-nitroimidazole for at least one week Standard triple treatment-Bismuth salt with two out of three of tetracycline, amoxicillin, and metronidazole for at least one week Quadruple treatment-Proton pump inhibitor plus standard triple treatment

- Dyspeptic symptoms or quality of life assessed as an outcome with previously validated measures

\section{Quality criteria}

- True random allocation

- Concealment of allocation

- Patient reliably blinded to treatment allocation

- Investigator reliably blinded to treatment allocation

- Analysis according to allocation, regardless of compliance (intention to treat)

- Percentages of participants excluded from al analysis

Where disagreements occurred a third reviewer was involved and the majority view taken. The quality of trials was evaluated according to predefined criteria (see box). The quality assessment focused on whether the methods used for randomisation, concealment of allocation, and blinding of participants and investigators were stated. Use of intention to treat analyses and completeness of follow up were also recorded, and the use of validated dyspepsia and quality of life measures was noted. Trials described as randomised but which did not state a method of randomisation were included.

\section{Data extraction}

A single investigator extracted data from eligible trials on a standardised form, which was checked by a second investigator. Data from intention to treat analyses were used whenever they were provided, and outcomes were recorded for the final assessment. Where dyspepsia outcomes were recorded in categories they were regrouped into an a priori dichotomy of those with improved (mild symptoms) or resolved dyspepsia (no symptoms) versus those with the same or worse dyspepsia (moderate or severe symptoms).
Dichotomies and scale measures of dyspepsia were recorded as reported, as were assessments of quality of life.

\section{Data synthesis}

We expressed the effect of eradication in each trial as a relative risk, comparing the numbers remaining dyspeptic in the eradication group with those in the comparison group. We pooled relative risks using a fixed effect (Mantel-Haenszel) model, the appropriateness of which we assessed using a test of homogeneity and of funnel plot asymmetry. ${ }^{8}$ We then converted the outcome to relative risk reduction $(100 \times(1-$ relative risk) $\%)$ and calculated the number needed to treat as: $100 /($ (relative risk reduction $) \times($ mean dyspepsia rate in placebo group)).

We estimated the impact of treatment on quality of life by combining standardised effect sizes because a mixture of instruments to measure quality of life had been used in the trials. All results were reported with $95 \%$ confidence intervals. We performed sensitivity analyses, using STATA (version 6.0), to investigate the impact of individual trials on the overall results. The review was undertaken according to a protocol published in the Cochrane Library and will be regularly updated as a Cochrane review as more information becomes available.

\section{Economic evaluation}

Using the computer program TreeAge version 3.5 (TreeAge Software, Williamstown, MA), we incorporated estimates from the systematic review into a Markov model (see $B M$ /s website for details) to establish the cost effectiveness of $H$ pylori eradication treatment in non-ulcer dyspepsia.

\section{Strategies compared in the model}

The model compared $H$ pylori eradication with one month of antacid treatment in patients with non-ulcer dyspepsia, with follow up over one year (the same duration as the trials). For the model, it was assumed that antacid treatment acted as an inexpensive placebo $^{9}$ and that patients whose symptoms continued despite treatment would be given advice on lifestyle and reassurance by their general practitioner but no additional treatment beyond the first month.

\section{Costs and benefits identified in the model}

The model evaluated the impact of $H$ pylori eradication from a health service perspective, incorporating the costs of drugs and visits to a general practitioner as given in published sources (table 1 ). The benefit of treatment was measured as the number of months of minimal or no dyspeptic symptoms during the year. The response rate at one year for those receiving antacids was estimated from the placebo group in the systematic review and converted into a monthly probability of recurrent dyspepsia. We applied the relative risk reduction from the review to estimate the response rate for those receiving $H$ pylori eradication treatment. We tested the robustness of the results in one way sensitivity analyses.

The main areas of uncertainty in the model are the estimate of the relative risk reduction and the maximum willingness to pay for one month free of dyspepsia We assumed that the relative risk of 
Table 1 Parameters used in Markov model evaluating cost effectiveness of Helicobacter pylori eradication treatment for non-ulcer dyspepsia

\begin{tabular}{|c|c|}
\hline Parameter & $\begin{array}{l}\text { Base case (range usec } \\
\text { in sensitivity } \\
\text { analyses) }\end{array}$ \\
\hline Cost of visit to general practice $(£)$ & $18^{*}(9-20)$ \\
\hline No of visits to general practice per year if dyspeptic & $3+(1-12)$ \\
\hline Cost of antacid treatment $(£)$ & $2.48(1.68-12.50) \ddagger$ \\
\hline Cost of $H$ pylori eradication treatment $(£)$ & $37.94(15.36-39.32) \S$ \\
\hline Antacid response rate at one year (\%) & 281 \\
\hline $\begin{array}{l}\text { Relative risk of dyspepsia with } \mathrm{H} \text { pylori eradication } \\
\text { treatment }\end{array}$ & $0.91(0.86-0.96)^{\star *}$ \\
\hline $\begin{array}{l}\text { Sources of data: } \\
{ }^{*} \text { Netten et al. }{ }^{10} \\
\dagger \text { †elaney et al. } .^{11} \\
\text { †Costs based on magnesium trisilicate } 10 \mathrm{ml} \text { four tim } \\
\text { case), magnesium carbonate } 10 \mathrm{ml} \text { four times daily fo } \\
\text { limit), Gaviscon Advance } 10 \mathrm{ml} \text { four times daily for } 30 \\
\text { limit). }{ }^{12} \\
\text { §Costs based on lansoprazole } 30 \mathrm{mg} \text { twice daily, clari } \\
\text { daily, and amoxicillin } 1 \mathrm{~g} \text { twice daily for } 7 \text { days (base } \\
\text { citrate } 400 \mathrm{mg} \text { twice daily, amoxycillin } 1 \mathrm{~g} \text { twice daily, } \\
400 \mathrm{mg} \text { twice daily for } 7 \text { days (lower range limit); and } \\
\text { daily, clarithromycin } 500 \mathrm{mg} \text { twice daily, and amoxicill } \\
\text { days. }{ }^{12} \\
\text { १Mean placebo response rate at one year in systemat } \\
{ }^{* *} \text { Relative risk and } 95 \% \mathrm{Cl} \text { obtained from systematic }\end{array}$ & $\begin{array}{l}\text { daily for } 30 \text { days (base } \\
30 \text { days (lower range } \\
\text { ays (upper range } \\
\text { omycin } 500 \mathrm{mg} \text { twice } \\
\text { e); ranitidine bismuth } \\
\text { id metronidazole } \\
\text { meprazole } 20 \mathrm{mg} \text { twice } \\
1 \mathrm{~g} \text { twice daily for } 7 \\
\text { eview. } \\
\text { jiew. }\end{array}$ \\
\hline
\end{tabular}

dyspepsia in patients given $H$ pylori eradication treatment had a log normal distribution with a mean and standard deviation derived from the pooled estimate from the meta-analysis. We then conducted a probabilistic sensitivity analysis using Monte Carlo simulation of $1000^{13}$ and repeated this analysis for high and low cost eradication regimens. We used an Excel 97 spreadsheet to construct a set of cost effectiveness acceptability curves to reflect uncertainty in both effects and the maximum willingness to pay. ${ }^{14-16}$

\section{Results}

Our initial search identified 5146 articles, but, after scanning titles and abstracts, we found only 47 trials that seemed to evaluate $H$ pylori eradication treatment in non-ulcer dyspepsia. Twelve of these trials met the eligibility criteria and were included in the systematic review (see $B M$ /s sebsite for details of studies). Ten trials compared $H$ pylori eradication treatment with placebo or placebo plus a proton pump inhibitor with follow up of 3-12 months. ${ }^{17-26}$ We considered the other two trials ${ }^{27} 28$ separately because they compared $H$ pylori eradication treatment with an alternative drug treatment and followed patients for only three months or less.

\section{Effect of $\boldsymbol{H}$ pylori eradication treatment on dyspepsia symptoms}

One trial ${ }^{22}$ did not give results as dichotomous outcomes, and we could not obtain this information from the authors. This trial evaluated 84 patients and reported no change in mean dyspepsia score between those randomised to $H$ pylori eradication treatment and those given placebo. The remaining nine trials ${ }^{17-21} 23-26$ evaluated a total of 2541 patients and defined dyspepsia cure as no symptoms or mild symptoms not interfering with daily activities. The mean placebo response rate at one year was 28\% (range 7-51\%), and the mean $\mathrm{H}$ pylori eradication treatment response rate was $36 \%$ (range $21-58 \%$ ). An unusually high placebo response rate was observed in two trials $^{21}{ }^{26}$ and two others included some patients with predominant reflux symptoms, ${ }^{17}{ }^{24}$ but there was no significant heterogeneity between the trial results (heterogeneity test $\chi^{2}=7.09, \mathrm{df}=8, \mathrm{P}=0.53$ ). There was also no evidence of funnel plot asymmetry.

Overall, there was a small but significant benefit of $H$ pylori eradication treatment at 12 months (relative risk reduction $9 \%(95 \%$ confidence interval $4 \%$ to $14 \%)$ ) (fig 1). The number of patients needed to treat with $H$ pylori eradication treatment to cure one extra case of non-ulcer dyspepsia was 15 (95\% confidence interval 10 to 31 ). The point estimate of the relative risk reduction did not vary by more than $2 \%$ and remained significant when any one trial was omitted from the analysis. The meta-analysis included several studies that were available in abstract and for which there were no full papers to review. When these were excluded in a sensitivity analysis the effect of $H$ pylori eradication on symptoms remained at a similar level (relative risk reduction $7 \%(1 \%$ to $12 \%))$.

Of the other two trials, Sheu et al compared bismuth subcitrate, amoxicillin, and metronidazole with $\mathrm{H}_{2}$ receptor antagonist in 41 patients with non-ulcer dyspepsia, ${ }^{27}$ and Dhali et al compared bismuth subcitrate, tetracycline, and metronidazole with sucralfate in 62 patients. ${ }^{28}$ Both trials used scale measures of dyspeptic symptoms and showed significant benefits of $H$ pylori eradication compared with the alternative treatment.

None of the trials formally evaluated individual dyspepsia symptoms, although two prospectively subdivided patients into the categories of ulcer-like and dysmotility-like dyspepsia. ${ }^{20}{ }^{21}$ Similar proportions of patients in these categories responded to $H$ pylori eradication treatment.

Effect of H pylori eradication on quality of life

Three trials presented data on quality of life at 12 months that were suitable for meta-analysis. Two trials used the psychological general wellbeing index, ${ }^{18}{ }^{20}$ and one used the SF-36. ${ }^{17}$ Overall, $H$ pylori eradication treatment had no significant effect on quality of life compared with placebo (standardised mean difference $0.01(95 \%$ confidence interval -0.12 to 0.15$)$ ).

\begin{tabular}{|c|c|c|c|c|c|}
\hline \multirow[b]{2}{*}{ Study } & \multicolumn{2}{|c|}{ No of patients still dyspeptic } & & & \multirow[b]{2}{*}{ Risk ratio $(95 \% \mathrm{Cl})$} \\
\hline & Treatment & Placebo & \multicolumn{2}{|c|}{ Risk ratio (95\% Cl) } & \\
\hline Blum et al ${ }^{18}$ & $119 / 164$ & $130 / 164$ & & & $0.92(0.81$ to 1.03$)$ \\
\hline Koelz et al ${ }^{19}$ & $67 / 89$ & $73 / 92$ & & & 0.95 (0.81 to 1.11$)$ \\
\hline McColl et a ${ }^{17}$ & $121 / 154$ & $143 / 154$ & & & 0.85 (0.77 to 0.93$)$ \\
\hline Talley et $\mathrm{al}^{20}$ & $101 / 133$ & $111 / 142$ & & & $0.97(0.85$ to 1.11$)$ \\
\hline Talley et al ${ }^{21}$ & $81 / 150$ & $72 / 143$ & & & 1.07 (0.86 to 1.34$)$ \\
\hline Miwa et $\mathrm{al}^{23}$ & $33 / 48$ & $28 / 37$ & & & 0.91 (0.70 to 1.18$)$ \\
\hline Malfertheiner et $\mathrm{al}^{24}$ & $269 / 460$ & $143 / 214$ & & & $0.88(0.77$ to 0.99$)$ \\
\hline Bruley des Varannes et $\mathrm{al}^{26}$ & $6 \quad 74 / 129$ & $86 / 124$ & & & 0.83 (0.68 to 1.00$)$ \\
\hline Froehlich et al ${ }^{25}$ & $31 / 74$ & $34 / 70$ & & & $0.86(0.60$ to 1.24$)$ \\
\hline \multirow[t]{2}{*}{ Total } & & & & & 0.91 (0.86 to 0.96$)$ \\
\hline & & & 0.75 & 1.25 & $\begin{array}{c}\mathrm{P}=0.0002 \\
\text { Test for } \\
\text { heterogeneity } \\
\mathrm{Q}=7.09, \mathrm{df}=8, \mathrm{P}=0.53\end{array}$ \\
\hline
\end{tabular}

Fig 1 Forest plot of the nine trials comparing $H$ pylori eradication treatment for non-ulcer dyspepsia with placebo 
Table 2 One way sensitivity analysis of Markov model evaluating cost effectiveness of Helicobacter pylori eradication treatment for non-ulcer dyspepsia

\begin{tabular}{|c|c|c|c|c|c|c|}
\hline \multirow[b]{2}{*}{ Variable altered } & \multicolumn{3}{|c|}{ Worst case scenario for $H$ pylori eradication } & \multicolumn{3}{|c|}{ Best case scenario for $\boldsymbol{H}$ pylori eradication } \\
\hline & Extra cost $(£)^{\star}$ & $\begin{array}{c}\text { Extra benefit } \\
\text { (symptom-free } \\
\text { months) } \dagger\end{array}$ & $\begin{array}{l}\text { Incremental cost } \\
\text { effectiveness } \\
\text { (£)‡ }\end{array}$ & Extra cost $(£)^{*}$ & $\begin{array}{c}\text { Extra benefit } \\
\text { (symptom-free } \\
\text { months) } \dagger\end{array}$ & $\begin{array}{c}\text { Incremental cost } \\
\text { effectiveness } \\
\text { (£)‡ }\end{array}$ \\
\hline Cost of visit to general practice & 33.61 & 0.563 & 60 & 31.35 & 0.563 & 56 \\
\hline $\begin{array}{l}\text { No of visits to general practice per year if } \\
\text { dyspeptic }\end{array}$ & 33.45 & 0.563 & 59 & 24.16 & 0.563 & 43 \\
\hline Cost of antacid treatment & 32.56 & 0.563 & 58 & 21.74 & 0.563 & 39 \\
\hline Cost of $\mathrm{H}$ pylori eradication treatment & 33.14 & 0.563 & 59 & 9.18 & 0.563 & 16 \\
\hline $\begin{array}{l}\text { Relative risk of dyspepsia with eradication } \\
\text { treatment }\end{array}$ & 33.79 & 0.256 & 132 & 29.79 & 0.856 & 35 \\
\hline
\end{tabular}

${ }^{*}$ Cost of $H$ pylori eradication-antacid strategy.

†Extra months free from dyspepsia with $H$ pylori eradication compared with antacid strategy.

flncremental cost of $H$ pylori eradication compared with antacid strategy per month free from dyspepsia.

Quality of trials included in review

All the trials that compared $H$ pylori eradication with placebo were double blind, placebo controlled, and with follow up of at least three months. Four trials described the population from which non-ulcer dyspepsia patients were recruited and stated the method of randomisation, ${ }^{17} 1820$ but only one mentioned the method used to conceal allocation at randomisation. ${ }^{18}$ All trials used validated dyspepsia questionnaires and excluded patients with confirmed peptic ulcer disease or oesophagitis before enrolment.

In four trials repeat endoscopy was performed at 12 months to ensure that patients remained free of peptic ulcer disease, ${ }^{18} 202126$ but only two reported these results: $6 / 164(4 \%)$ and $7 / 143(5 \%)$ of patients taking placebo developed peptic ulcer disease at 12 months' follow up compared with $1 / 164(0.6 \%)$ and $3 / 150(2 \%)$ in the treatment groups. ${ }^{18}{ }^{21}$ Although repeat endoscopy was not part of the protocol of the McColl trial, ${ }^{17}$ nine patients underwent endoscopy during follow up because of persistent symptoms: all three patients in the treatment group had normal results, whereas four of the six patients in the placebo group had peptic ulcer disease.

Two trials reported endoscopic oesophagitis as an outcome measure at 12 months, ${ }^{18}{ }^{29}$ and these found oesophagitis to be slightly more common in the patients allocated to $H$ pylori eradication treatment. However, these events were relatively rare $(17 / 297$ $(6 \%)$ in the treatment group and $9 / 306(3 \%)$ in the placebo group), and the difference between the groups was not significant (relative risk 2.07 (0.94 to 4.56$)$ ).

\section{Cost effectiveness analysis}

Our cost effectiveness analysis estimated that $H$ pylori eradication would be $£ 31.76$ more expensive per patient per year than the antacid strategy (cost of antacid strategy $£ 55.25$, cost of $H$ pylori eradication strategy £87.01) but that patients receiving $H$ pylori eradication treatment would benefit by an average of an extra 0.56 months free from dyspepsia than those given antacid. This yielded an incremental cost effectiveness ratio of $£ 56$ per extra month free from dyspepsia. This finding was robust to all one way sensitivity analyses except for the size of relative risk reduction (table 2).

The decision as to whether $H$ pylori eradication treatment is cost effective in non-ulcer dyspepsia depends on the maximum willingness to pay for each month free of dyspepsia and the uncertainty that the decision maker is willing to tolerate. This is shown in the cost effectiveness acceptability curve (fig 2). If a decision maker is willing to accept a $20 \%$ chance of the policy being incorrect, then, for a maximum willingness to pay of $£ 75$ a month free of dyspepsia, the "base case scenario" would be acceptable. If the maximum acceptable cost were $£ 25$, then only cheaper eradication regimens would be cost effective.

\section{Discussion}

The results of our systematic review are based on well designed and executed randomised trials. The trials were usually large, with no evidence of imbalance in baseline characteristics. Outcomes were assessed with validated dyspepsia questionnaires; drop out rates were low; and intention to treat analyses were reported for extended follow up.

The meta-analysis estimated a significant 9\% reduction in the number of patients with non-ulcer dyspepsia remaining dyspeptic after the use of $H$ pylori eradication treatment. Of the nine trials included in this analysis, only three reported a significant benefit of eradication treatment. ${ }^{174}{ }^{24}$ While there has been lively debate about the apparent differences in the results of these trials, ${ }^{30}$ there is in fact no evidence of statistical heterogeneity in their results so the differences may be explained by chance. None of the nine trials had sufficient power to detect treatment benefits as small as that observed in this meta-analysis. Our overall result is also supported by the two small trials that showed a benefit for $H$ pylori eradication treatment at 2-3 months over $\mathrm{H}_{2}$ receptor antagonists ${ }^{27}$ or sucralfate ${ }^{28}$ in non-ulcer dyspepsia patients.

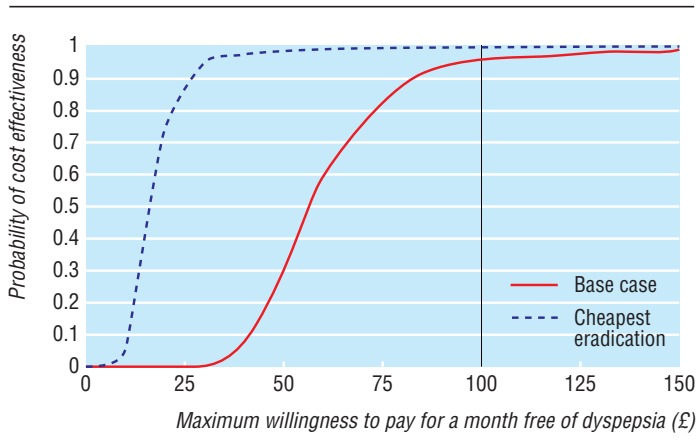

Fig 2 Cost effectiveness acceptability curve of $H$ pylori eradication treatment for non-ulcer dyspepsia 


\section{What is already known on this topic}

The efficacy of $H$ pylori eradication treatment for non-ulcer dyspepsia is controversial

Randomised controlled trials have given conflicting results

Previous systematic reviews have suggested that such treatment might be of benefit, but they did not include all relevant trials or evaluate cost effectiveness of treatment

\section{What this study adds}

H pylori eradication is of small but statistically significant benefit for dyspepsia symptoms of patients with non-ulcer dyspepsia

An estimated 15 infected patients would need $H$ pylori eradication treatment to cure one extra case of non-ulcer dyspepsia

Despite the small clinical effect, $H$ pylori eradication treatment might be a cost effective intervention for non-ulcer dyspepsia

The mechanism by which $H$ pylori eradication treatment reduces dyspepsia symptoms in patients with nonulcer dyspepsia is unclear. ${ }^{31} \mathrm{H}$ pylori causes most gastric and duodenal ulcers, and the therapeutic effect noted in this meta-analysis might be due to the treatment of undiagnosed peptic ulcer disease. All patients underwent endoscopy before entry into the trials to exclude peptic ulcer disease, but in this relapsing and remitting disorder patients with an ulcer diathesis do not always have an ulcer associated with their dyspepsia. ${ }^{32}{ }^{33}$ This is emphasised by the observation that $4 \%$ of the patients enrolled into the placebo groups of two of the trials we reviewed developed peptic ulcer disease during follow up. $H$ pylori eradication treatment may therefore be effective only in treating the small subset of patients with peptic ulcer disease that has been misclassified as non-ulcer dyspepsia. This possibility does not invalidate our conclusion: pragmatically, patients with dyspepsia and normal results on endoscopy gain a modest benefit from $H$ pylori eradication.

\section{Cost effectiveness of eradication}

The effect of H pylori eradication treatment on dyspeptic symptoms in non-ulcer dyspepsia is small, and so it is important to evaluate whether it is cost effective. As a baseline estimate, our Markov model suggested H pylori eradication cost an extra $£ 56$ for each month free from dyspepsia in patients with non-ulcer dyspepsia. The model was constructed to provide a conservative estimate of cost effectiveness. We did not extend the effect of treatment beyond the length of the trials, although benefits should continue to accrue. The model compared H pylori eradication treatment with antacid, as definitive evidence for the effectiveness of more expensive treatments such as antisecretory or prokinetic treatment is lacking. ${ }^{34}$ We have also not assessed the potential for increasing antimicrobial resistance rates, as the additional impact of treating non-ulcer dyspepsia on the present rate of antibiotic prescribing in the community is likely to be small. ${ }^{35}$ The Markov model applies only to patients with non-ulcer dyspepsia diagnosed after endoscopy and should not be extrapolated directly to the management of undiagnosed dyspepsia.

Data from observational studies have suggested that $H$ pylori eradication treatment may increase the incidence of reflux disease.$^{36}$ However, the randomised controlled trials in our meta-analysis did not report a significant increase in reflux symptoms or oesophagitis with eradication treatment, and we did not include gastro-oesophageal reflux in the model.

Non-ulcer dyspepsia is a common problem that is distressing for patients and responsible for a substantial healthcare costs. ${ }^{37}$ Treating the infection could be cost effective provided a cost of $£ 75$ per month free from dyspepsia is acceptable. This cut off point is open to debate, and more research is needed into the willingness to pay for relief of dyspepsia symptoms. If cheaper $H$ pylori eradication regimens were used the cost would be less than $£ 25$ per month free from dyspepsia. To place this in context, this is half the cost of long term treatment of gastro-oesophageal reflux disease with antisecretory treatment. ${ }^{38}$

The Dyspepsia Review Group comprised Adam Harris, Department of Gastroenterology, Kent and Sussex Hospital, Tunbridge Wells; Brendan Delaney, Michael Innes, Rachel Oakes, Richard Hobbs, and Sue Wilson, Department of Primary Care and General Practice, University of Birmingham; David Forman, Cochrane Upper Gastrointestinal and Pancreatic Diseases Group, University of Leeds; James Mason, Centre for Health Economics, University of York; James Raftery and Pelham Barton, Birmingham Health Economic Facility, Health Services Management Centre, Birmingham; Jonathan Deeks, ICRF/NHS Centre for Statistics in Medicine, Institute of Health Sciences, Oxford; Paul Moayyedi and Shelly Soo, Gastroenterology Unit, Centre for Digestive Diseases, The General Infirmary at Leeds.

We thank all the experts in the field who responded to our request for information. We thank Professor Malfertheiner, Dr Fuchs, Dr Froehlich, and Dr Miwa for providing us with additional information about their trials and are particularly indebted to Dr Koeltz for providing details of the results of the FROSCH study. We thank Pelham Barton for his advice on conversion of risks to rates in the Markov model.

Contributors: PM developed the protocol, assessed eligibility of trials, performed data extraction and the economic analysis, and co-wrote the manuscript. SS reviewed the literature, performed most of the eligibility assessments and data extraction, and reviewed the manuscript. JD developed the protocol, checked the eligibility assessments and data extraction, performed the statistical analyses, and co-wrote the manuscript. JM helped develop the economic model and co-wrote the manuscript. MI helped review the literature and reviewed the manuscript. DF developed the protocol and co-wrote the manuscript. BD was lead applicant, chaired the study group, developed the protocol, checked eligibility assessments, performed the economic modelling, and co-wrote the manuscript. PM and BD are guarantors for the study.

Funding: The NHS Executive Research and Development, Health Technology Assessment Programme funded this review and modelling exercise (project No 96/37/01). The views expressed in the paper are the opinions of the authors and do not necessarily reflect those of the NHS Executive. PM holds a UK Medical Research Council Health Services Research Training Fellowship. BD holds an NHS R\&D National Primary Care Career Scientist Award. The Cochrane UGPD Group is funded by the NHS R\&D Directorate.

Competing interests: PM is an independent medical adviser to AstraZeneca.

1 Hosking SW, Ling TK, Chung SC, Yung MY, Cheng AF, Sung JJ, et al Duodenal ulcer healing by eradication of Helicobacter pylori without anti-acid treatment: randomised controlled trial. Lancet 1994;343:508-10.

2 Talley NJ. A critique of therapeutic trials in Helicobacter pylori-positive functional dyspepsia. Gastroenterology 1994;106:1174-83.

3 Jaakkimainen RL, Boyle E, Tudiver F. Is Helicobacter pylori associated with non-ulcer dyspepsia and will eradication improve symptoms? A meta-analysis. BMJ 1999;319:1040-4 
4 Danesh J, Pounder RE. Eradication of Helicobacter pylori and non-ulcer dyspepsia. Lancet 2000;355:766-7.

5 Laine L, Schoenfeld M, Fennerty B. H pylori is not effective for treatment of non-ulcer dyspepsia: meta-analysis of randomised controlled trials [abstract]. Gastroenterology 2000;118:A440.

6 Colin-Jones DG. Management of dyspepsia: report of a working party. Lancet $1988 ;$ i:576-9.

7 Talley NJ, Colin-Jones DG, Koch KL, Koch M, Nyren O, Stanghellini V. Functional dyspepsia: a classification with guidelines for diagnosis and management. Gastroenterology Int 1991;4:145-60.

8 Egger M, Davey SG, Schneider M, Minder C. Bias in meta-analysis detected by a simple, graphical test. BMJ 1997;315:629-34.

9 Nyren O, Adami HO, Bates S, Bergstrom R, Gustavsson S, Loof L, et al. Absence of therapeutic benefit from antacids or cimetidine in non-ulcer dyspepsia. N Engl J Med 1986;314:339-43.

10 Netten A, Dennett J, Knight J. Unit costs of health and social care. Canterbury: University of Kent, 1998.

11 Delaney BC, Wilson S, Roalfe A, Redman V, Roberts L, Hobbs RFD. A primary care-based RCT of early endoscopy for dyspepsia in patients of 50 years of age and over [abstract]. Gut 1999;45(suppl V):A87.

12 British Medical Association, Royal Pharmaceutical Society of Great Britain. British national formulary. London: BMA, RPS, 1999. (No 37.)

13 Doubillet P, Begg CB, Weinstein MC, Braun P, McNeil BJ. Probabilistic sensitivity analysis using Monte Carlo simulation. Med Decision Making 1985;5:157-77.

14 Van Hout BA, Al MJ, Gordon GS, Rutten FF. Costs, effects and C/E ratios alonoside a clinical trial Health Econ 1994:3.309-19.

15 UK Prospective Diabetes Study Group. Cost effectiveness analysis of improved blood pressure control in hypertensive patients with type 2 diabetes: UKPDS 40. BMJ 1998;317:720-6.

16 Briggs AH, Gray AM. Handling uncertainty when performing economic evaluation of healthcare interventions. Health Technol Assess 1999;3(2).

17 McColl K, Murray L, el-Omar E, Dickson A, El-Nujumi A, Wirz A, et al. Symptomatic benefit from eradicating Helicobacter pylori infection in patients with nonulcer dyspepsia. N Engl J Med 1998;339:1869-74

18 Blum AL, Talley NJ, O'Morain C, Veldhuyzen van Zanten S, Labenz J, Stolte M, et al for the Omeprazole plus Clarithromycin and Amoxycillin Effect One Year after Treatment (OCAY) Study Group. Lack of effect of treating Helicobacter pylori infection in patients with nonulcer dyspepsia. N Engl J Med 1998;339:1875-81.

19 Koelz HR, Arnold R, Stolte M, Fischer M, Blum AL. Symptomatic response to treatment of Helicobacter pylori in functional dyspepsia. Randomized double-blind trial with 6 months follow-up [abstract]. Gastroenterology 1998;114:A182.

20 Talley NJ, Janssens J, Lauritsen K, Racz I, Bolling-Sternevald E. Eradication of Helicobacter pylori in functional dyspepsia: a randomised double blind placebo controlled trial with 12 months' follow up. BMJ 1999:318:833-7.

21 Talley NJ, Vakil N, Ballard II ED, Fennerty MB. Absence of benefit of eradicating Helicobacter pylori in patients with nonulcer dyspepsia. $N$ Engl J Med 1999;341:1106-11.

22 Greenburg PD, Cello JP. Lack of effect of treatment for Helicobacter pylori on symptoms of nonulcer dyspepsia. Arch Intern Med 1999;159:2283-8.
23 Miwa H, Hirai S, Nagahara A, Murai T, Nishira T, Kikuchi S, et al. Cure of Helicobacter pylori infection does not improve symptoms in non-ulcer dyspepsia patients - a double-blind placebo-controlled study. Aliment Pharmacol Ther 2000;14:317-24.

24 Malfertheiner P, Fischbach W, Layer P, Moessner J, Stolte M, Leodolter A, et al. Elan study proves symptomatic benefit of Helicobacter pylori eradication in functional dyspepsia [abstract]. Gastroenterology 2000;118:A440.

25 Froehlich F, Gonvers J-J, Wietlisbach V, Burnand B, Hildebrand P, Schneider C, et al. Helicobacter pylori eradication treatment does not benefit patients with non-ulcer dyspepsia [abstract]. Gastroenterology 2000;118:A469.

26 Bruley des Varannes S, Flejou JF, Colin R, Zaim M, Meunier A. Helicobacter pylori eradication in non-ulcer dyspepsia: a randomized, double-blind, placebo-controlled study with a 12-month follow-up [abstract]. Gastroenterology 2000;118:A468.

27 Sheu BS, Lin CY, Lin XZ, Shiesh SC, Yang HB, Chen CY. Long-term outcome of triple therapy in Helicobacter pylori-related nonulcer dyspepsia: a prospective controlled assessment. Am J Gastroenterology 1996;91:441-7.

28 Dhali GK, Garg PK, Sharma MP. Role of anti-Helicobacter pylori in treatment in $\mathrm{H}$ pylori-positive and cytoprotective drugs in $\mathrm{H}$ pylori-negative, non-ulcer dyspepsia: results of a randomized, double blind, controlled trial in Asian Indians. J Gastroenterol Hepatol 1999;14:523-8.

29 Talley NJ, Janssens J, Lauritsen K, Rácz I, Bolling-Sternevald E, Have N, et al. No increase in reflux symptoms in patients with non-ulcer dyspepsia 12 months after Helicobacter pylori eradication. A randomized double-blind placebo-controlled trial [abstract]. Digestion 1998;59:7.

30 McColl KEL, Gillen D, Dickson AS, Talley NJ, Lauritsen K, Bolling-Sternevald E. Eradication of Helicobacter pylori in functional dyspepsia [letter]. BMJ 1999;319:451.

31 Talley NJ, Hunt RH. What role does Helicobacter pylori play in dyspepsia and nonulcer dyspepsia? Arguments for and against H. pylori being associated with dyspeptic symptoms. Gastroenterology 1997;113:S67-77.

32 Gibinski K. Step by step towards the natural history of peptic ulcer disease. J Clin Gastroenterol 1983;5:299-302.

33 Isenberg JI, Peterson WL, Elashoff JD, Sandersfeld MA, Reedy TJ, Ippoliti $\mathrm{AF}$, et al. Healing of benign gastric ulcer with low-dose antacid or cimetidine. A double-blind, randomized, placebo-controlled trial. $N$ Engl J Med 1983;308:1319-24

34 Veldhuyzen van Zanten S, Cleary C, Talley NJ, Peterson TC, Nyren O, Bradley LA, et al. Drug treatment of functional dyspepsia: a systematic analysis of trial methodology with recommendations for design of future trials. Am J Gastroenterol 1996;91:660-73.

35 Axon ATR, Forman D. Helicobacter gastroduodenitis: a serious infectious disease. BMJ 1997;314:1430-1

36 Labenz J, Blum AL, Bayerdorffer E, Meining A, Stolte M, Borsch G. Curing Helicobacter pylori infection in patients with duodenal ulce may provoke reflux esophagitis. Gastroenterology 1997;112:1442-7.

37 Moayyedi P, Axon ATR. Is there a rationale for eradication of Helicobacter pylori? Cost-benefit: the case for. Br Med Bull 1998;54: 243-50

38 Bate CM, Richardson PDI. A one-year model for the cost-effectiveness of treating reflux oesophagitis. Br J Med Econ 1992;2:5-11.

(Accepted 21 June 2000)

\section{A paper that changed our practice Which postcoital contraceptive?}

A few weeks ago my senior partner presented the results of a paper published in the Lancet $^{1}$ comparing the standard Yuzpe method for postcoital contraception (combined oestrogen and progesterone) with two doses of progesterone only (levonorgestrel $0.75 \mathrm{mg}$ ). Until now the latter has required women to take large numbers of tablets, but a formulation in two single tablets has become available in the United Kingdom (Levonelle-2). A large number of women requesting emergency contraception were studied, 1998 enrolled, and the outcomes were known for 1955 of these. The results seemed to be quite clear cut: fewer pregnancies following the progesterone only regimen and also fewer adverse effects.

The overall pregnancy rate was found to be $3.2 \%$ of women given Yuzpe but only 1.1\% of those randomised to levonorgestrel. This represents a relative risk of 0.36 , and the size of the trial meant that the $95 \%$ confidence interval of 0.18 to 0.70 was narrow enough to exclude the null hypothesis of no difference between treatments. Vomiting was also significantly less common, occurring in 19\% of women given the Yuzpe regimen and 6\% given levonorgestrel $(\mathrm{p}<0.01)$

A single study may be contradicted by other trials, so I decided to check this out further in the Cochrane Library and found a review covering emergency contraception which was updated in March 1999.' The review found two randomised controlled trials which compared levonorgestrel and Yuzpe (including the World
Health Organization study in the Lancet). The results of the two studies were similar, and the pooled relative risk of pregnancy with levonorgestrel was 0.51 (95\% CI 0.31 to 0.84 ) when compared with Yuzpe. The pooled risk of pregnancy with the Yuzpe regimen is 3.2\% across the two trials, so the number needed to treat with levonorgestrel rather than Yuzpe to prevent one pregnancy is 63 (95\% CI 45-193). Similarly, since levonorgestrel induces fewer side effects, only seven patients need to be given this rather than Yuzpe (95\% CI 7-8) to prevent one from vomiting.

Although the new treatment is more expensive, we estimated that switching to levonorgestrel from Yuzpe would cost about $£ 200$ per extra pregnancy prevented. This compares favourably with the cost and inconvenience of a termination of pregnancy which would otherwise be needed after failed postcoital contraception. We have changed our practice.

Christopher Cates general practitioner, Watford

1 Task Force on Postovulatory Methods of Fertility Regulation. Randomised controlled trial of levonorgestrel versus Yuzpe regimen of combined oral contraceptives for emergency contraception. Lancet 1998;352:428-33.

2 Cheng L, Gülmezoglu AM, Ezcurra E, Van Look PFA. Interventions for emergency contraception. (Cochrane Review). In: Cochrane Library, Issue 2. Oxford: Update Software, 2000 